\title{
COMUNICAÇÃO
}

\section{OCORRÊNCIA DE Zaprionus indianus Gupta, 1970 (Diptera: Drosophilidae) NO ESTADO DE MINAS GERAIS}

\author{
Occurrence of Zaprionus indianus Gupta, 1970 (Diptera: Drosophilidae) in Minas Gerais State
}

\author{
Carlos Massaru Kato', Lúcia Victor Foureaux², Renata Araújo César ${ }^{3}$, Marina Portugal Torres ${ }^{4}$
}

\begin{abstract}
RESUMO
Foi reportada a ocorrência do drosofilídeo Zaprionus indianus Gupta, 1970, nos municípios de Belo Horizonte, Contagem, Fortuna de Minas, João Pinheiro, Dom Bosco, Vargem Grande do Rio Pardo, Paracatu, Manga, Verdelândia, Montes Claros, Janaúba, Jaíba e Nova Lima, Estado de Minas Gerais, Brasil. Essa espécie de mosca foi coletada em armadilhas para Strategus sp. (Coleoptera: Scarabaeidae), com atrativo constituído por bagaço de cana e melaço e em armadilhas "MacPhail". Foi observada também causando injúrias em frutos de carambola.
\end{abstract}

Termos para indexação: Insecta, drosofilídeo, carambola, figo.

\section{ABSTRACT}

The occurrence of the drosophilid Zaprionus indianus Gupta, 1970, in Belo Horizonte, Contagem, Fortuna de Minas, João Pinheiro, Dom Bosco, Vargem Grande do Rio Pardo, Paracatu, Manga, Verdelândia, Montes Claros, Janaúba, Jaíba and Nova Lima, Minas Gerais State, Brazil was reported. This species of fly was found on traps to collect Strategus sp. (Coleoptera: Scarabaeidae) with sugarcane bagasse and cane molasse as atractive, and "MacPhail". It was also observed causing injuries on a carambola fruit.

Index terms: Insecta, drosophilid, carambola fruit, fig.

(Recebido para publicação em 6 de fevereiro de 2003 e aprovado em 3 de junho de 2003)

Analisando amostras de insetos coletadas em armadilhas contendo atrativo à base de bagaço de cana e melaço, com a finalidade de monitorar o coleóptero Strategus sp. (Coleoptera: Scarabaeidae) na Fundação Zoobotânica de Belo Horizonte - MG, foram observadas moscas da família Drosophilidae. Os insetos foram identificados por Carlos Massaru Kato, do Laboratório de Diagnóstico Fitossanitário em Insetos, do Instituto Mineiro de Agropecuária, como sendo a mosca-africana-do-figo Zaprionus indianus Gupta, 1970 (Diptera: Drosophilidae).

Após essa observação, foram analisadas também amostras de insetos coletadas em armadilhas tipo "MacPhail", abastecidas com proteína hidrolizada, provenientes do monitoramento de moscas-das-frutas realizado no Estado de Minas Gerais pelo Instituto Mineiro de Agropecuária e pelo Ministério da Agricultura, Pecuária e Abastecimento. Além disso, amostras de frutos enviadas por produtores ao laboratório foram analisadas criteriosamente com relação a esse inseto.

A mosca-do-figo foi encontrada alimentando-se de frutos de carambola provenientes do município de Conta- gem, inviabilizando-os para o consumo. No município de Fortuna de Minas, foi capturada em armadilhas "MacPhail" instaladas em pomar de lima-ácida Tahiti. Em João Pinheiro, Dom Bosco, Vargem Grande do Rio Pardo, Verdelândia, Montes Claros, Janaúba e Jaíba, armadilhas tipo "MacPhail" capturaram o drosofilídeo em pomares de manga, nos municípios de Paracatu e Manga, em área de produção de cucurbitáceas e, em Nova Lima, em pomar doméstico constituído de várias frutíferas.

O gênero Zaprionus Coquillett, 1901, é composto por dois subgêneros com 56 espécies, sendo $Z$. indianus a única que está se espalhando pelas regiões tropicais do mundo, em razão provavelmente da intensificação do comércio mundial de frutas. Ela está distribuída por toda África e já foi observada nas Ilhas Comores, Madagascar, Seychelles, Reunião e Macarenhas no Oceano Índico, nas Ilhas Canárias e Santa Helena no Oceano Atlântico, Índia, Arábia Saudita e Brasil (STEIN et al., 2002).

No Brasil, o primeiro registro sobre a ocorrência de Z. indianus foi comunicado por Vilela (1999) e Vile-

\footnotetext{
1. Engenheiro Agrônomo, MSc., LDFI/IMA, BR-040, km 527, 32145-970 - Contagem, MG.

2. Bióloga, MSc., LDFI/IMA.

3. Estagiária-LDFI/IMA, estudante de Ciências Biológicas - PUC/BH - MG.

4. Engenheira Agrônoma-FZB/BH, Av. Otacílio N. Lima, 8000 - 31365-970 - Belo Horizonte, MG.
} 
la et al. (1999), quando observaram larvas desse drosofilídeo infestando frutos de caqui no município de Santa Isabel, Estado de São Paulo. Stein et al. (2002) detectaram, na região de Valinhos/SP, a mosca-do-figo alimentando-se e ovipositando em frutos de figo da cultivar roxo-de-valinhos. Silva e Marchiori (2002) realizaram em Minas Gerais, nos meses de novembro e dezembro de 2001, um levantamento de parasitóides de pupas de Z. indianus na Universidade Federal de Lavras, na cidade de Lavras, supondo-se, com isso, que o drosofilídeo já se encontrava presente no Estado desde essa época.

Apesar de a mosca-do-figo possuir diversos frutos como hospedeiro, ela só é considerada limitante na cultura do figo, a ponto de muitos ficicultores da região de Campinas/SP, abandonarem seus pomares durante a safra de 2000/2001 (RAGA et al., 2002).

Esse inseto, recentemente introduzido no Brasil, encontrou condições favoráveis ao seu estabelecimento e desenvolvimento, atingindo rapidamente o "status" de praga nas principais regiões produtoras de figo do Estado de São Paulo, provocando perdas de até $50 \%$ da produção (STEIN et al., 2002).

Por causa dessas características, a mosca-do-figo Z. indianus está sendo considerada pelo Ministério da Agricultura, Pecuária e Abastecimento como praga quarentenária A2. Portanto, torna-se necessário um levantamento desse inseto em todo o Estado, principalmente nas regiões produtoras de figo, como nos municípios de São Sebastião do Paraíso, Jacuí, Pratápolis, Carmo do Rio Claro, Monte Santo de Minas, Lavras, Caldas, Santa Rita de Caldas, Perdões, Três Pontas, Uberaba e Araxá (ANTUNES et al., 1997), a fim de caracterizá-las áreas livres ou de baixa prevalência dessa mosca.

\section{AGRADECIMENTOS}

Ao chefe do Serviço de Sanidade Vegetal da Delegacia Federal da Agricultura de Minas Gerais do Ministério da Agricultura, Pecuária e Abastecimento, Dr.
Francisco Roberto de Pinho, e ao chefe da Divisão de Defesa Sanitária Vegetal da Superintendência de Produção Vegetal do Instituto Mineiro de Agropecuária, Dr. Airton Rigueira Bezerra, pela autorização do envio deste trabalho para publicação, cumprindo-se, assim, Portaria Ministerial para publicações de ocorrências de pragas quarentenárias no Brasil.

\section{REFERÊNCIAS BIBLIOGRÁFICAS}

ANTUNES, L. E. C.; ABRAHÃO, E.; SILVA, V. J. da. Caracterização da cultura da figueira no Estado de Minas Gerais. Informe Agropecuário, Belo Horizonte, v. 18, n. 188 , p. 43-44, 1997.

RAGA, A.; SOUZA FILHO, M. F.; SATO, M. E. A mosca-do-figo está sendo pesquisada no Instituto Biológico. Disponível em: <http://www.biológico.br/ceib/ a_mosca.htm>. Acesso em: 17 jul. 2002.

STEIN, C. P.; TEIXEIRA, E. P.; NOVO, J. P. S. Mosca-do-figo - Zaprionus indianus. Disponível em: <http://www.url:../cenfit/artigos/zaprionus>. Acesso em: 17 jul. 2002.

SILVA, C. G.; MARCHIORI, C. H. Spalangia endius (Walker) (Hymenoptera: Pteromalidae) in pupae of Zaprionus indianus Gupta (Diptera: Drosophilidae) in Brazil. Disponível em: <http://www.univap.br/inic2002/inic_resumo_2.htm >. Acesso em: 03 set. 2002.

VILELA, C. R. Is Zaprionus indianus Gupta, 1970 (Diptera, Drosophilidae) currently colonizing the Neotropical Region?. [S.1.: s.n.], 1999.

VILELA, C. R.; TEIXEIRA, E. P.; STEIN, C. P. Nova praga nos figos: Zaprionus indianus Gupta, 1970. Informativo da Sociedade Entomológica do Brasil, São Paulo, v. 24, n. 2, p. 2, ago. 1999. 